\title{
PATIENTS' SATISFACTION OF SURGERY FOR RESISTANT CASES OF DE QUERVAIN'S DISEASE
}

\author{
DAS KP ${ }^{1}$, TALUKDAR DC ${ }^{2}$, CHOWDHURY RM ${ }^{3}$, ANOWARUL ISLAM A ${ }^{4}$, DATTA NK ${ }^{5}$, SHOMA FK ${ }^{6}$, \\ ISLAM MN ${ }^{7}$
}

\begin{abstract}
Background: De Quervain's disease or stenosing tenosynovitis of the first dorsal compartment of the wrist is a common wrist pathology. Pain results from resisted gliding of the abductor pollicis longus and the extensor pollicis brevis tendons in the fibro-osseous canal. Management of resistant cases of de Quervain's disease by surgical decompression yield satisfactory outcomes.

Materials and Method: This prospective study was conducted in the department of orthopaedic surgery BSMMU, Dhaka between the periods of January 2009 to October 2011. 45 patients with 50 de Quervain's disease who did not respond to conservative treatment were operated under local anesthesia with tourniquet control. Follow up period was 3 months to 3 years.

Results: Most of our patients were female 42 (93.33\%), housewife 27 patients involving 30 hands (60\%) with mean age of 38.60 years, ranging from 22-64 years. Right sided involvement was 28 (56\%), left sided involvement was 12 (24\%) and both sided involvement was 5 patients involving 10(20\%) hands. Pain at the radial side of the wrist in 50 (100\%), swelling 30 (60\%) and restricted thumb movement in 50 (100\%) were the predominant symptoms. 01(02\%) patient/ hand developed chronic tenosynovitis, 01(02\%) patient/hand developed infection followed by hypertrophic scar and 3(6\%) patients/hands developed temporary loss of sensation along the distribution of superficial branch of the radial nerve. . There was no recurrence in the follow-up period. Satisfactory result was found in 48 (96\%) operated hand.

Conclusion: Surgical release of tendons of the first compartment of wrist is an easy, safe, effective, economic and acceptable procedure for patients with resistant cases of de Quervain's tenosynovitis .
\end{abstract}

Key words: Patient Satisfaction, de Quervain's disease, resistant cases, surgery. J Dhaka Med Coll. 2011; 20(2) : 146-152.

\section{Introduction:}

De Quervain's disease is a condition brought on by irritation or swelling of the tendons found along the thumb side of the wrist ${ }^{1}$. The irritation causes the compartment (lining) around the tendon to swell, changing the shape of the compartment; this makes it difficult for the tendons to move as they should. The swelling can cause pain and tenderness along the thumb side of the wrist, usually noticed when forming a fist, grasping or gripping things, or turning the wrist. The pain is usually described by patients as a very sharp, stabbing pain. It is not subtle. Although many physicians call this "tendonitis" (which means an inflammatory condition of the tendons), actually inflammation is not a key component of the problem ${ }^{2}$.

The two tendons concerned are the tendons of the extensor pollicis brevis and abductor pollicis longus muscles. These two muscles, which run side by side, have almost the same function: the movement of the thumb away from the

1. Dr. Krishna Priya Das, Assistant Professor, Department of Orthopaedics, BSMMU, Dhaka.

2. Dr. Debesh Chandra Talukdar, Assistant Professor, Department of ENT, DMCH, Dhaka.

3. Dr. Rumpa Mani Chowdhury, Resident, Department of Neonatology, BSMMU, Dhaka.

4. Dr. Anowarul Islam, Assistant Professor, Department of Orthopaedics, BSMMU.

5. Dr. Nakul Kumar Datta, Professor and Chairman, Department of Orthopaedics, BSMMU, Dhaka

6. Dr. Farzana Khan Shoma, Assistant Professor, Department of Physical Medicine, BIHS Hospital

7. Dr. Md. Nazrul Islam, Assistant Registrar, Department of Vascular Surgery, NICVD, Dhaka.

Correspondence to: Dr. Krishna Priya Das, Assistant Professor, Hand and Reconstructive Surgery Unit, Department of Orthopaedic Surgery, Bangabandhu Sheikh Mujib Medical University (BSMMU), Dhaka-1000, Bangladesh, Mobile: 01816356806, e-mail: kdas33@yahoo.com 
hand in the plane of the hand, so called radial abduction (as opposed to movement of the thumb away from the hand, out of the plane of the hand (palmar abduction)). The tendons run, as do all of the tendons passing the wrist, in synovial sheaths, which contain them and allow them to exercise their function whatever the position of the wrist. Evaluation of histological specimens shows a thickening and myxoid degeneration consistent with a chronic degenerative process ${ }^{3}$. The pathology is identical in de Quervain seen in new mothers ${ }^{4}$. de Quervain's is more common in women; the speculative rationale for this is that women have a greater angle of the styloid process of the radius ${ }^{2}$. The cause of de Quervain's disease is not known. In medical terms, it remains idiopathic. Some claim that this diagnosis should be included among overuse injuries and that repetitive movements of the thumb are a contributing factor, but there are no scientific data that support a link between hand use and de Quervain's disease ${ }^{6}$.

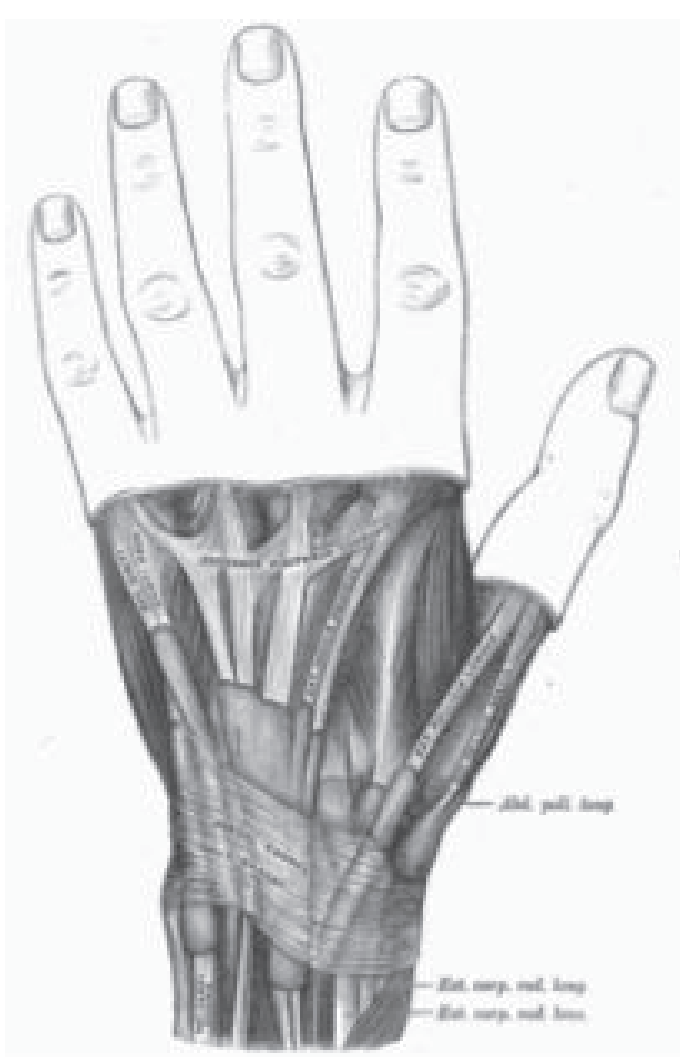

Fig.-1: Arrangement extensor tendon of the left wrist.
Symptoms are pain, tenderness, and swelling over the thumb side of the wrist, and difficulty gripping. Finkelstein's test ${ }^{5,6}$ is used to diagnose de Quervain syndrome in people who have wrist pain. To perform the test, the examining physician grasps the thumb and the hand is ulnar deviated sharply, as shown in the image. If sharp pain occurs along the distal radius (top of forearm, about an in inch below the wrist; see image), deQuervain's syndrome is likely.

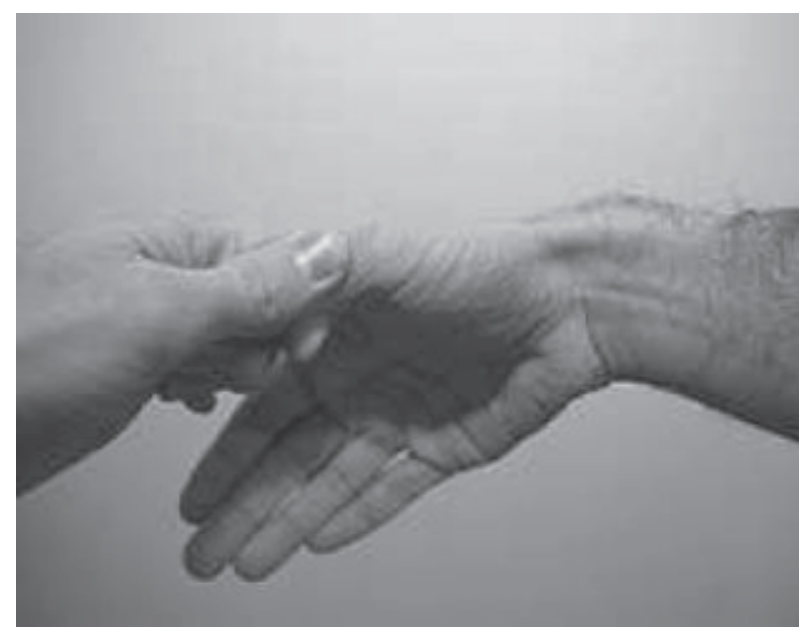

Fig.-2: Finkelstein's test.

The management of de Quervain's disease is determined more by convention than scientific data. From the original description of the illness in 1895 until the first description of corticosteroid injection by Jarrod Ismond in $1955^{7}$, it appears that the only treatment offered was surgery ${ }^{[7,8,9]}$. Since approximately 1972 the prevailing opinion has been that of McKenzie (1972) who suggested that corticosteroid injection was the first line of treatment and surgery should be reserved for unsuccessful injections ${ }^{10}$. However, data regarding the efficacy of corticosteroid injection is sparse and uncontrolled (Oxford Level of Evidence 4) and it is not clear that there is a benefit over the natural history of the illness. A structured review published in 2003 identified only 35 publications that addressed De Quervain's on Medline, only 7 of which presented data regarding corticosteroid 
injection, and none of which were controlled studies $^{11}$.

Retrospective studies all report success rates for corticosteroid injection greater than $70 \%$, but the one prospective cohort study noted a success rate of only 58\% and many of those patients took 12 to 18 months until symptom resolution ${ }^{12}$. While the authors of that study ascribed the failure of corticosteroid injection to anatomical variations, it has not been clearly established that corticosteroid injection is better than placebo or that a symptom course of 12 to 18 months is any better than the natural course of the illness.

Another commonly used criterion for failure of non-operative treatment is election of operative treatment, but the decision to operate is complex and biased by the beliefs and emotions of the surgeon and the patient. Use of an elective event such as surgery to define success makes data regarding nonoperative treatment difficult to interpret. For instance, in one of the two investigations in which a substantial number of patients were treated without injection (splints and antiinflammatory medication alone were used), a remarkable 45 of 93 (48\%) of patients in all nonoperative treatment groups had surgery ${ }^{13}$. This may simply reflect frustration on the part of both the patient and the surgeon with the prolonged symptom course associated with the disease. It may appear to both patient and surgeon that, after many months of symptoms, the illness will never resolve. The data of Lane and colleagues ${ }^{14}$ indicating that non-operative treatment is successful only in mild cases is similarly marred by the lack of patients randomly assigned to alternative treatments and the use in many patients of a decision for surgery as a failure criterion.

Most tendinoses are self-limiting and the same is likely to be true of de Quervain's although further study is needed. One retrospective series documented resolution in $90 \%$ of patients within 1 year ${ }^{15}$.Palliative treatments include a splint that immobilized the wrist and the thumb to the interphalangeal joint and anti-inflammatory medication or acetaminophen.

Surgery (in which the sheath of the first dorsal compartment is opened longitudinally) is documented to provide relief in most patients ${ }^{13}$. The most important risk is to the radial sensory nerve.

Physical/Occupational Therapy often focuses on lifting mechanics even though there is no evidence that activity modification can alter the course of the illness ${ }^{6}$. Therapists can help fashion a splint that provides relief of symptoms by immobilizing the wrist and thumb. Splints have not been demonstrated to change the course of the illness.

\section{Materials and Method:}

This prospective study was conducted in the department of Orthopaedic surgery BSMMU, Dhaka between the periods of January 2009 to October 2011.50 patients with de Quervain's disease who did not respond to conservative treatment were operated under local anesthesia with pneumatic tourniquet control. Follow up period was 3 months to 3 years.

\section{Results:}

Most of our patients were female 42 (93.33\%), housewife 27 involved 30 hands (60\%) with mean age of 38.60 years, ranging from 22-64 years. Right sided involvement was 28 (56\%), left sided involvement was $12(24 \%)$ and both sided involvement was $10(20 \%)$. Pain at the radial side of the wrist in $50(100 \%)$, swelling $30(60 \%)$ and restricted thumb movement in $50(100 \%)$ were the predominant symptoms. 2 (4\%) patients developed chronic tenosynovitis, $1(2 \%)$ patient developed infection followed by hypertrophic scar and 3(6\%) patients developed temporary loss of sensation along the distribution of superficial branch of the radial nerve. . There was no recurrence in the followup period. Satisfactory result was found in 48 patients (96\%). 
Statistics:

Table-I

Age, Sex and side of involvement of de Quervain's tenosynovitis.

\begin{tabular}{lcccccc}
\hline $\begin{array}{l}\text { Age } \\
\text { group } \\
\text { (in years) }\end{array}$ & $\begin{array}{c}\text { Total pt } \\
(\mathrm{N}=45\end{array}$ & $\begin{array}{c}\text { Female } \\
(\mathrm{n}=42,\end{array}$ & $\begin{array}{l}\text { Male } \\
(\mathrm{n}=3,\end{array}$ & \multicolumn{3}{c}{ Total hand 50 (100\%) } \\
\hline $22-31$ & $07(15.56 \%)$ & $93.33 \%)$ & $06.67 \%)$ & $\begin{array}{c}\text { Bilateral } \\
\text { 5pt, 10 hands(20\%) }\end{array}$ & $\begin{array}{c}\text { Right } \\
28(56 \%)\end{array}$ & $\begin{array}{c}\text { Left } \\
12(24 \%)\end{array}$ \\
$32-41$ & $19(42.22 \%)$ & 18 & 01 & $02(04 \%)$ & $03(06 \%)$ & $03(06 \%)$ \\
$42-51$ & $11(24.44 \%)$ & 10 & 01 & $04(12 \%)$ & $12(24 \%)$ & $04(08 \%)$ \\
$52-64$ & $08(17.78 \%)$ & 08 & 00 & $02(04 \%)$ & $07(14 \%)$ & $03(06 \%)$ \\
\hline
\end{tabular}

Mean Age \pm SD (Range) $=36.60 \pm 8.6(22-64)$

Sex, Female: Male $=14: 01$

Side of involvement, Right: Left $=2: 1$

Table-II

Occupation of the patients

\begin{tabular}{lcc}
\hline $\begin{array}{l}\text { Name of the } \\
\text { occupation }\end{array}$ & $\begin{array}{c}\text { Total no } 45 \\
\text { of patients }\end{array}$ & $\begin{array}{c}\text { No of hands } \\
50(100 \%)\end{array}$ \\
\hline Housewife & 27 & $30(60 \%)$ \\
Garments worker & 07 & $08(16 \%)$ \\
House hold worker & 05 & $06(12 \%)$ \\
Computer operator & 03 & $03(06 \%)$ \\
Others & 03 & $03(06 \%)$ \\
\hline
\end{tabular}

Table-III

Distribution of Symptoms and Signs

\begin{tabular}{lc}
\hline Symptoms and Signs & Frequency (Percent) \\
\hline Pain & $50(100 \%)$ \\
Swelling & $30(60 \%)$ \\
Restricted movement of thumb & $49(98 \%)$ \\
Finkelstein's test & $50(100 \%)$ \\
\hline
\end{tabular}

Table-III

Distribution of study subjects according to disability

\begin{tabular}{lc}
\hline Disability & Frequency (Frequency) \\
\hline Unable to wash clothes & $50(100 \%)$ \\
Difficulty in wrenching clothes & $48(96 \%)$ \\
Difficulty in holding the object & $46(92 \%)$ \\
Difficulty in Combing hair & $21(42 \%)$ \\
Difficulty in Use key board & $04(08 \%)$ \\
\hline
\end{tabular}

Table-V

Previous treatment history

\begin{tabular}{lcc}
\hline Form of treatment & Frequency & Percent \\
\hline NSAID & 50 & 100 \\
Rest and splinting & 10 & 20 \\
Ultrasound therapy & 15 & 30 \\
Steroid injection & 45 & 90 \\
\hline
\end{tabular}

Table-VI

Associated medical condition ( $n=50$ hand)

\begin{tabular}{lcc}
\hline $\begin{array}{l}\text { Associated medical } \\
\text { condition }\end{array}$ & Frequency & Percent \\
\hline $\begin{array}{l}\text { Idiopathic } \\
\text { (Not associated with }\end{array}$ & 34 & 68 \\
other diseases) & & \\
Rheumatoid arthritis & 6 & 12 \\
Hypothyroidism & 3 & 06 \\
Obesity & 2 & 04 \\
Diabetes mellitus & 5 & 10 \\
\hline
\end{tabular}

Table-VII

Complication

\begin{tabular}{lcc}
\hline Complication & $\begin{array}{c}\text { Frequency } \\
(\mathrm{n}=50)\end{array}$ & $\begin{array}{c}\text { Percent } \\
(100 \%)\end{array}$ \\
\hline Radial sensory nerve injury & & \\
-neuropraxia & 03 & 06 \\
-axontmesis & 00 & 00 \\
-neurotmesis & 00 & 00 \\
Chronic tenosynovitis & 01 & 02 \\
Superficial wound infection & 01 & 02 \\
Hypertrophic scar & 01 & 02 \\
Recurrent disease & 00 & 00 \\
\hline
\end{tabular}


Table-VIII

Comparison of pre operative and post operative pain measured on Visual Analogue Scale . $^{6}$

\begin{tabular}{lccc}
\hline Visual analogue scale $(0-10 \mathrm{~cm})$ & Pain before treatment & Pain after treatment & P value* \\
\hline Mean \pm SD & $4.82 \pm 0.92$ & $0.12 \pm 0.42$ & 0.001 \\
(Range) & $(4.00-7.00)$ & $(0.00-2.00)$ & \\
\hline
\end{tabular}

*Paired $t$ test was done to measure the level of significance. Here $p=0.001(<0.005)$ is highly significant.

Table-IX

Comparison of pre operative and post operative thumb movement ${ }^{6}$.

\begin{tabular}{lccc}
\hline Movement of the thumb & Before treatment & After treatment & p value* \\
\hline Abduction(in degree) & $15.00 \pm 3.12$ & $56.94 \pm 6.44$ & 0.001 \\
Maximal thumb flexion $^{* *}$ (distance in $\mathrm{mm}$ ) & $32.52 \pm 2.52$ & $20.62 \pm 1.12$ & 0.001 \\
\hline
\end{tabular}

*Paired $t$ test was done to measure the level of significance. Here $p=0.001$ which is highly significant. **values indicate distances between thumb tip and ulnar border of distal palmar crease.

Table-X

Comparison of Finkelstein's test before and after treatment ${ }^{16}$

\begin{tabular}{lcc}
\hline Finkelstein's test & $\begin{array}{c}\text { Before } \\
\text { treatment }\end{array}$ & $\begin{array}{c}\text { After } \\
\text { treatment }\end{array}$ \\
\hline Positive & $50(100 \%)$ & $01(02 \%)$ \\
Negative & $00(00 \%)$ & $49(98 \%)$ \\
\hline
\end{tabular}

\section{Preoperative Photograph}

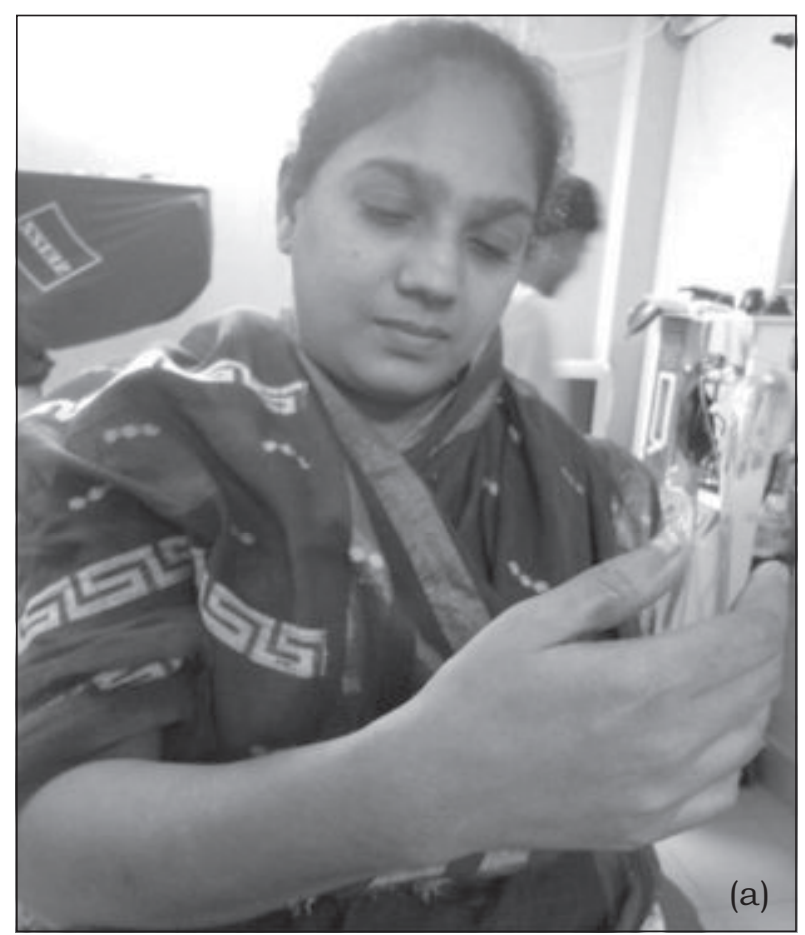

\section{Table-XI}

Overall outcome

\begin{tabular}{lcc}
\hline Result & $\begin{array}{c}\text { Total No. of } \\
\text { patients }(\mathrm{n}=50)\end{array}$ & $\begin{array}{c}\text { Percent } \\
(100 \%)\end{array}$ \\
\hline Satisfaction & 48 & 96 \\
Dissatisfaction & 02 & 04 \\
\hline
\end{tabular}

'P value $=0.001$

$Z$ proportion test was done to measure the level of significance.

Satisfaction was significantly higher $(p=0.001)$ than dissatisfaction.

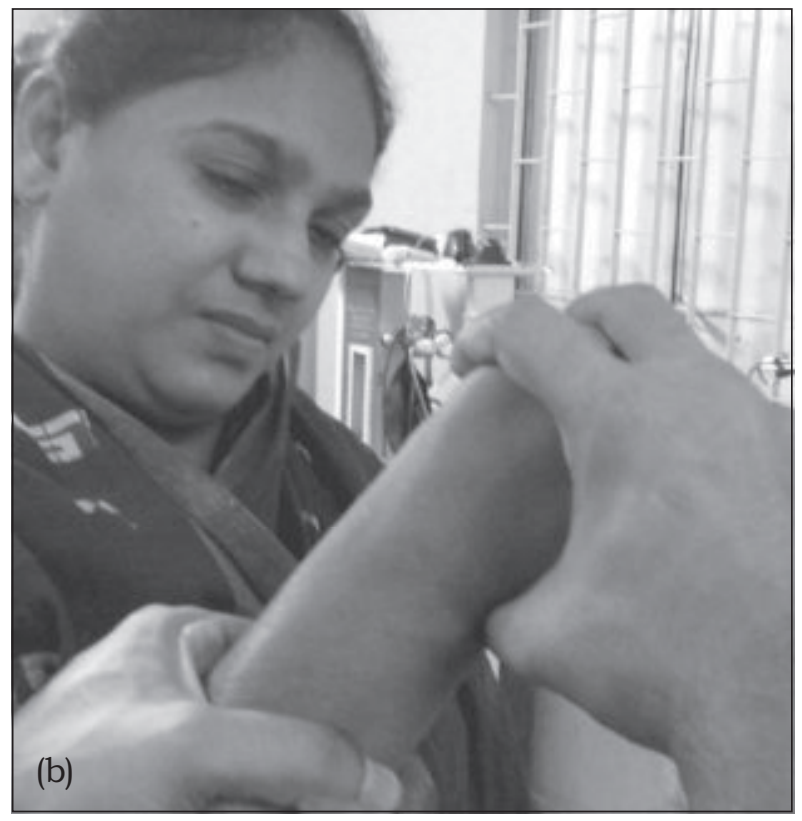

a- painful swelling at the radial side of the wrist. $b$ - Finkelstein's test positive 

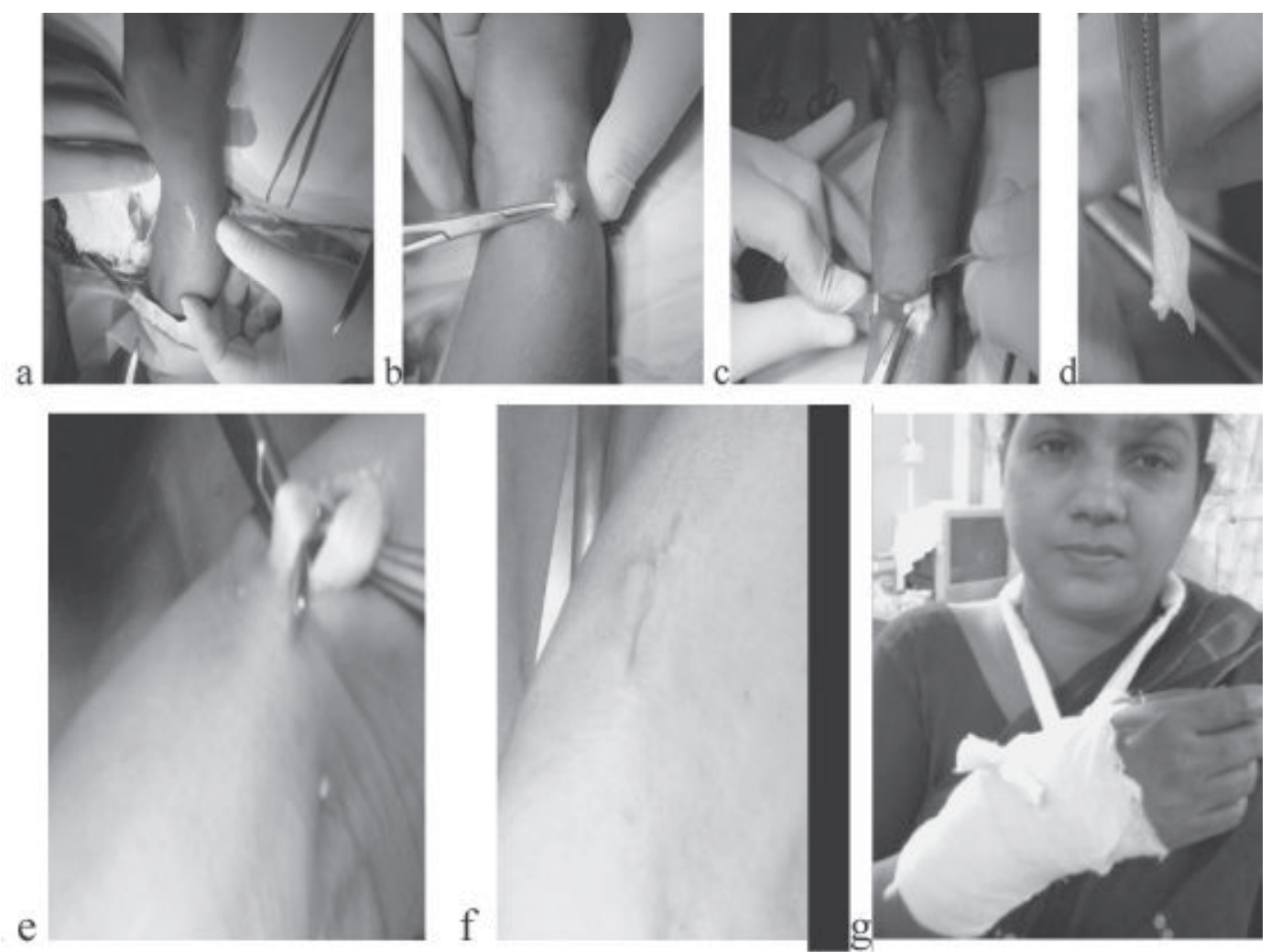

Peroperative: $a$-incision mark, $b$ - superficial $b r$. of radial nerve, $c \& d$ - thickened tendon sheath, e-extensor pollicis brevis and abductor pollicis longus tendon, $f$ after closer, $g$-dressing with elevation of the hand (Rt).

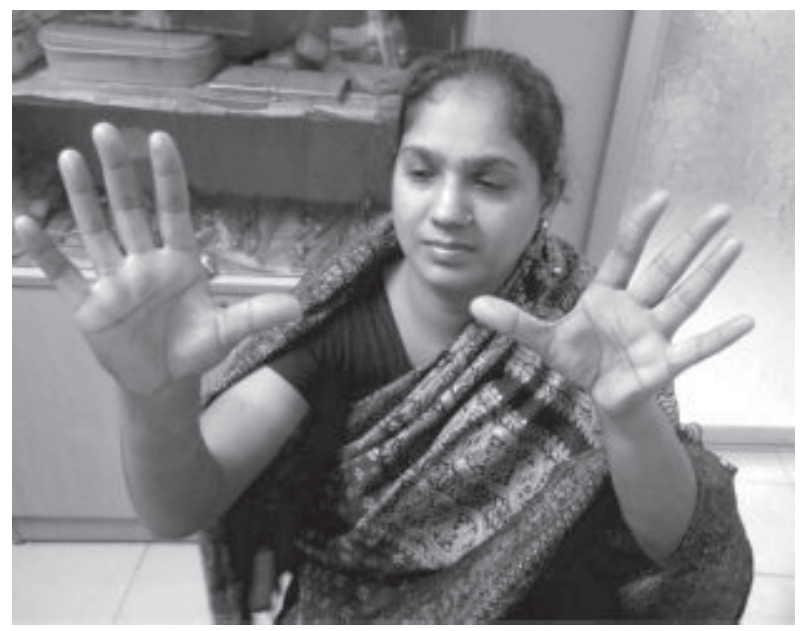

Final follow up at 3 months.

\section{Discussion:}

This study was carried out on 45 patients (50 hands) with resistant cases of de Quervain's tenosynovitis treated by surgical de compression. Age ranges between 22-64 years. Mean $\pm \mathrm{SD}=36.60 \pm 8.6$ years. Average age of different series was 38 years $^{1}, 47.5$ years $^{6}, 48$ years ${ }^{7}$. As the disease is more common between 30-50 years ${ }^{3}$, our study also showed $35(77.78 \%)$ patients were presented in $26-50$ years age group, reason could be during this period individual carries out greatest physical effort ${ }^{7}$. Male female ratio was $1: 14$, it corresponds with the study of Zarin (2003), Ta (1999), Timothy (1953) ${ }^{9}$. Affection in female was significantly higher than male ${ }^{7}$.

In this series $60 \%$ patients were housewife, $16 \%$ patients were garments worker, $12 \%$ patients were household worker and 06\% patients were computer operator. This disease was significantly higher in the housewife, the probable cause would be the repeated use of thumb and ulnar deviation of wrist leading to chronic trauma and increased friction to the tendon sheath becomes thickened ${ }^{9}$. Out of 50 hands, $10 \%$ patients had diabetes mellitus, $6 \%$ patients had hypothyroidism, $6 \%$ patient had rheumatoid arthritis and 4\% patients were 
suffering from obesity but $68 \%$ of cases no cause was identified. ${ }^{10}$

In our study $06 \%$ cases had developed neuropraxia of the superficial branch of radial nerve for transient period ${ }^{15}$ and $02 \%$ of cases developed wound infection, lead to hypertrophic scar but one $(02 \%)$ cases developed chronic synovitis, where post operative persistent pain, tenderness, swelling were present and Finkelstein's test was also positive. That patient was improved after re exploration. On the basis of Forget $\mathrm{N}$ et al criteria ${ }^{6}$ pre operative and post operative mean pain score was 4.82 (range 4 to 7 ) and 0.12 (range 0.00to 2.00) and p value was 0.001 which was highly significant. Post operative thumb movement also significantly $(\mathrm{p}=0.001)$ improved in comparison with pre operative thumb movement ${ }^{6}$.

A cure for de Quervain's disease has been described by many investigators as the resolving of symptoms without complication or recurrent disease on follow-up evaluation[ $1,3,6,15,16]$. Finkelstein and Lapidus and Fenton reported the cure rate by surgery to be $92 \%$ and $91 \%$ respectively ${ }^{[3,15,16]}$. Our results closely agree with these observations. In our series, $96 \%$ of all patients who had surgery for de Quervain's tenosynovitis were cured, with no long-term complication or recurrent disease on follow-up evaluation. Excluding recurrent disease, we found the operative complication rate to be $04 \%$ for de Quervain's release. While steroid injection is still recommended as the initial therapy for de Quervain's tenosynovitis, the findings of this study indicate that surgery is still a safe and effective treatment for de Quervain's disease ${ }^{[15,16]}$.

\section{Conclusion}

Surgical release of tendons of the first compartment of wrist is an easy, safe, effective, economic and acceptable procedure even for patients with resistant cases of de Quervain's tenosynovitis.

\section{Reference:}

1. Ilyas A, Ast M, Schaffer AA, Thoder J (2007). "De quervain tenosynovitis of the wrist". J Am Acad Orthop Surg 15 (12): 757-64.

2. Ahuja NK, Chung KC (2004). "Fritz de Quervain, MD (1868-1940): stenosing tendovaginitis at the radial styloid process". J Hand Surg [Am] 29 (6): 1164-70.

3. Finkelstein H. "stenosing tendovaginitis at the radial styloid process."Journal of Bone joint surgery Am;12 (2):507-540.

4. Read HS, Hooper G, Davie R (February 2000). "Histological appearances in post-partum de Quervain's disease". J Hand Surg [Br] 25 (1): 702 .

5. Mayo Clinic. "De Quervain's tenosynovitis:Tests and diagnosis". http://www.mayoclinic. com/ health / de-quervains-tenosynovitis / DS00692/ DSECTION=tests-and-diagnosis.

6. Forget N, Piotte F, Arsenault J, Harris P, Bourbonnais D. "Bilateral thumb's active range of motion and strength in de Quervain's disease: Comparison with a normal sample". J. Hand Ther 2008 july-sep;21(3): 276-84:quiz 285.

7. Local hydrocortisone in de Quervain's disease. Br Med J 1955 Jun 25;1(4929):1501-3.

8. Piver JD, Raney RB. De Quervain's tendovaginitis. Am J Surg 1952 Mar;83(5):691-4.

9. Lamphier TA, Long NG, Dennehy T. De Quervain's disease: an analysis of 52 cases. Ann Surg 1953 Dec;138(6):832-41.

10. McKenzie JM. Conservative treatment of de Quervain's disease. Br Med J 1972 Dec 16;4(5841):659-60.

11. Corticosteroid injection for treatment of de Quervain's tenosynovitis: a pooled quantitative literature evaluation. J Am Board Fam Pract 2003 Mar-Apr;16(2):102-6.

12. Witt J, Pess G, Gelberman RH. Treatment of de Quervain tenosynovitis. A prospective study of the results of injection of steroids and immobilization in a splint. J Bone Joint Surg Am. 1991 Feb;73(2):219-22.

13. Weiss AP, Akelman E, Tabatabai M. Treatment of de Quervain's disease. J Hand Surg [Am] 1994 Jul;19(4):595-8.

14. Lane LB, Boretz RS, Stuchin SA. Treatment of de Quervain's disease:role of conservative management. J Hand Surg [Br] 2001 Jun;26(3):25860.

15. Kent T. Ta, MD, Dov Eidelman, MD, J. Grant Thomson, MD, New Haven, CT. "Patient Satisfaction and Outcomes of Surgery for de Quervain's Tenosynovitis". Am J Hand Surg 1999;24A:1071-1077.

16. Scheller A, Schuh R, Honle W, Schuh A. " Long term results of surgical release of de Quervain's stenosing tenosynovitis". International Orthopaedics 2009; 33: 1301-1303. 